\title{
Educação musical e formação de professores de música na Argentina
}

Gislene Marino

Júlio Emílio Diniz-Pereira

Recebido em 18/09/2018

Aprovado em 18/11/2018 
Este artigo baseia-se em estudos sobre formação de professores de música na Argentina que estão sendo desenvolvidos no Doutorado Latino-americano em Educação (FaE/UFMG). O texto apresenta algumas leis e políticas educacionais argentinas, a partir dos anos de 1990, destacando-se os pontos que impactam a educação musical escolar e a formação de professores. Expõem-se aspectos do ensino de música dentro do Sistema Educativo Nacional argentino, no qual a música integra a modalidade educação artística da educação infantil ao ensino superior. Para tratar da formação de professores de música na Argentina, trazem-se características das instituições formadoras e de aspectos que regulamentam os cursos, além de se destacarem os modelos de educação musical (SHIFRES; GONNET, 2015) e de formação de professores de música (MATEIRO, 2010) encontrados em países latino-americanos que afetam o ensino de música na Argentina.

Palavras-chave: Políticas educacionais; Educação musical escolar; Formação de professores de música na Argentina.

\section{INTRODUÇÃO}

Este artigo trata da educação musical e da formação de professores de música na Argentina ${ }^{1}$, a partir da legislação vigente e das características do ensino de música dentro do Sistema Educativo Nacional argentino. Tem-se como objetivo responder às questões - Quais impactos as políticas educacionais têm trazido para a formação de professores de música da Argentina? Como o ensino de música se faz presente no sistema educacional no país? Os modelos de educação musical (SHIFRES; GONNET, 2015) e de formação de professores de música (MATEIRO, 2010) latinoamericanos podem ser encontrados no contexto argentino?

As políticas educacionais têm se configurado como um

1 Este texto baseia-se em estudos sobre a formação de professores de música na Argentina, que estão sendo realizados no Doutorado Latino-americano em Educação, na Faculdade de Educação da Universidade Federal de Minas Gerais. Pesquisa com bolsa do PCRH/FAPEMIG. 
tema predominante nas pesquisas desenvolvidas na Argentina, enquanto incide a invisibilidade sobre aspectos relativos às ideias pedagógicas, às práticas educativas e à história da formação docente (AISENSTEIN et al., 2017). Busca-se, portanto, neste artigo, estabelecer um diálogo entre as políticas educacionais argentinas implementadas nos últimos anos, a educação musical escolar e a formação de professores de música.

\section{POLÍTICAS EDUCACIONAIS NA ARGENTINA}

Há inúmeras leis e resoluções que definem as diretrizes que organizam e dão suporte à educação e à formação docente na Argentina. Data de 1884 a Ley n. 1.420 que estruturou o desenvolvimento do sistema educacional argentino e gerou um conjunto de políticas que caracterizaram a reforma educativa no país. Em 1993, a Ley Federal de Educación n. 24.195 substituiu a Ley n. 1.420 e, além de renovar os conteúdos curriculares por meio da definição dos Conteúdos Básicos Curriculares (CBC), estabeleceu os objetivos e o locus da formação de professores, implantou políticas compensatórias e institucionalizou um sistema nacional de qualidade da educação. Em um contexto no qual o pensamento neoliberal predominou, a Ley n. 24.049/1991, conhecida como Ley de Transferencia, passa a responsabilidade sobre as instituições formadoras da jurisdição nacional para as províncias e a municipalidade de Buenos Aires. A transferência foi realizada sem que se definisse o papel do estado nacional sobre a formação docente e a integração do sistema formador. As políticas foram elaboradas por técnicos, não havendo participação das instituições educacionais nas definições e implementações das reformas (FELDFEBER, 2010). A formação docente sofreu adequações para que se atendessem aos conteúdos básicos para o ensino nas escolas e os professores foram considerados meros executores das medidas instauradas de fora para dentro (MISURACA; MENGHINI, 2010).

A Ley Nacional de Educación Superior n. 24.521/1995, ainda em vigor, definiu que a formação de professores para os distintos 
níveis de ensino deveria realizar-se em universidades ou em instituições não universitárias reconhecidas, que integrem a Red Federal de Formación Docente Continua. Segundo Feldfeber (2010), com a implantação do Sistema Nacional de Acreditación de Instituciones de Formación Docente e a criação de um órgão público de avaliação e acreditação universitária - a Comisión Nacional de Evaluación y Acreditación Universitaria (CONEAU) - o governo assumiu funções de regulação e controle. Para Misuraca e Menghini (2010), os mecanismos disciplinadores e competitivos que foram instalados, caracterizaram o pensamento neoliberal e a lógica mercantil.

Em 2006, a Ley de Educación Nacional n. 26.206 substituiu a Ley n. 24.195/1993, estabelecendo os novos objetivos da política educativa nacional, sob o preceito de que "a educação e o conhecimento são um bem público e um direito pessoal e social, garantidos pelo Estado" (ARGENTINA, 2006). Tal lei definiu a estrutura do Sistema Educativo Nacional, compreendendo quatro níveis - Educação Inicial, Educação Primária, Educação Secundária e Educação Superior - e oito modalidades: educação artística, educação técnico-profissional, educação especial, educação permanente de jovens e adultos, educação rural, educação intercultural bilíngue, educação em contextos de privação de liberdade, e educação domiciliar e hospitalar. No que se refere à formação docente, apresentou as finalidades e os ciclos para a formação de professores, fixando a duração mínima de quatro anos para os cursos que preparam docentes para os níveis inicial e primário. Além disso, a Ley n. 26.206 criou o Instituto de Formación Docente (INFD) cujas funções são reorganizar o sistema formador, fortalecer as relações entre ele e os diversos níveis do sistema educacional, coordenar ações de acompanhamento e avaliação das políticas, dentre outras, definindo-o como um organismo regulador nacional.

Os Lineamientos Curriculares Nacionales para la Formación Docente Inicial, aprovados em 2007, são um marco que regula e antecipa os desenhos curriculares e as práticas de formação docente inicial para todos os níveis e modalidades 
do Sistema Educativo Nacional. Eles buscam integrar o currículo de formação de professores, assegurando resultados equivalentes nas diversas províncias que proporcionem a mobilidade dos estudantes e o reconhecimento nacional da titulação dos egressos (ARGENTINA, 2007a). A Resolución CFE n. 74/2008 e a Resolución CFE n. 183/2012 - que aprovaram e modificaram, respectivamente, o Cuadro de Nominaciones de Títulos - proporcionaram a unificação da nomenclatura expedida na titulação dos professores, eliminando as múltiplas denominações dos títulos concedidos nas distintas províncias da Argentina que traziam problemas como a não aceitação de títulos em todo o território argentino (ARGENTINA, 2008, 2012). Há também planos nacionais para a formação docente que foram elaborados para os períodos compreendidos entre 2007-2010 e 2016-2021 que apontam metas para as políticas nacionais de formação de professores na Argentina, abarcando instituições de gestão estatal e privada (ARGENTINA, 2007b, 2016).

Apesar das críticas ao neoliberalismo acentuarem-se a partir dos anos 2000, as políticas educacionais na Argentina caracterizamse, ainda, de acordo com Feldfeber e Gluz (2011), pela coexistência de tendências de continuidade e de mudanças em relação às políticas hegemônicas da década de 1990. Enquanto adotam-se tecnologias de gestão características do âmbito privado - como concorrência para acesso a fundos públicos e imputação de um caráter competitivo à capacitação de professores (MISURACA; MENGHINI, 2010) - observa-se uma abertura para a participação mais ativa dos docentes, proporcionando-lhes um maior protagonismo (FELDFEBER, 2010).

\section{EDUCAÇÃO ARTÍSTICA E MÚSICA NO SISTEMA EDUCATIVO NACIONAL ARGENTINO}

A educação artística é uma das oito modalidades de formação que compõem o Sistema Educativo Nacional argentino. O artigo 40 da Ley 26.206 explicita o valor da educação artística, prevendo que todos/as os/as alunos/as recebam uma 
educação artística de qualidade que "fomente e desenvolva a sensibilidade e a capacidade criativa de cada pessoa, em um marco de valorização e proteção do patrimônio natural e cultural, material e simbólico das diversas comunidades que integram a Nação" (ARGENTINA, 2006, p. 13).

A educação artística é oferecida em três segmentos, compreendendo: i) a formação em distintas linguagens artísticas para crianças e adolescentes, em todos os níveis e modalidades (pelo menos duas disciplinas artísticas durante a escolaridade obrigatória); ii) a modalidade artística orientada para a formação específica de Nível Secundário (os alunos que optarem pela modalidade artística terão formação específica em música, dança, artes visuais, plástica, teatro) e, iii) a formação artística ensinada pelos Institutos de Educação Superior nos profesorados das diversas linguagens artísticas e nas carreiras artísticas específicas, de acordo com a Ley de Educación Nacional de 2006 (ARGENTINA, 2006). Na Argentina, assim como em outros países da América Latina, os cursos de formação de professores são designados profesorados, que correspondem às licenciaturas no Brasil, enquanto os cursos designados licenciaturas, equivalem aos nossos bacharelados (MATEIRO, 2010).

Assim sendo, a música é uma das linguagens artísticas previstas para a formação dentro dos três segmentos apontados. Na Educação Inicial, Primária e no Ciclo Básico da Educação Secundária, a música figura entre as modalidades da educação artística, mas tem seus objetivos e conteúdos próprios explicitados em diversos documentos oficiais. Temse, como exemplo, o Diseño Curricular para la Educación Primaria elaborado na Província de Buenos Aires, no qual a seção dedicada à educação artística traz reflexões sobre a Arte na escola, objetivos do seu ensino e direcionamentos pedagógicos. O ensino de música é proposto a partir de três eixos - elementos da linguagem musical, organização musical e produção musical - em que se apontam conceitos, conteúdos e indicadores de progresso do aluno (LA PLATA, 2018). Há 
também a Resolución 141/2011 que aprovou os Núcleos de Aprendizajes Prioritarios para la Educación Secundaria nas áreas de educação artística, educação física, educação tecnológica e formação ética e cidadã. O anexo II desse documento trata da educação artística e na seção dedicada à música encontram-se dois eixos, sendo um sobre a relação entre as práticas musicais e seu contexto, e outro sobre a relação das práticas musicais e sua produção (ARGENTINA, 2011).

No Ciclo Orientado, no âmbito da Educação Secundária, a educação artística - incluindo a música - tem como objetivos: a participação ativa e autônoma em práticas artísticas; o desenvolvimento de estratégias que permitam a interpretação de manifestações artísticas atuais dentro de uma perspectiva crítica; a participação em produções artísticas de caráter grupal; a abordagem de problemáticas específicas do campo artístico em relação ao mundo do trabalho; e a discussão sobre os novos modos de produção, circulação e construção de aprendizagens definidos pelas tecnologias digitais. Nesse Ciclo, aprofundamse os conhecimentos de música, especialmente no que se refere à interpretação vocal e instrumental e aos processos de improvisação, composição e produção de arranjos musicais (ARGENTINA, 2012).

No terceiro segmento, tem-se a formação em educação artística em nível superior preparando profissionais para a docência ou para as carreiras artísticas. Apesar de a música estar inserida na modalidade educação artística, o ensino de música e a formação de professores têm um tratamento específico em diretrizes, planejamentos curriculares e outros documentos oficiais. A música está presente nos três segmentos dentro do processo educacional argentino, abarcando a Educação Infantil, Primária e Secundária, o Ciclo Orientado e a formação em nível terciário ou superior, em que se objetiva tanto a formação do intérprete quanto a do professor de música. 


\section{FORMAÇÃO DE PROFESSORES DE MÚSICA NA ARGENTINA}

A história da formação de professores na Argentina remete-se à criação das antigas escolas normais, no final do século XIX, quando houve o processo de expansão e desenvolvimento do sistema de educação e instrução pública e o Estado passa a responsabilizar-se pela formação sistemática do professor (ALLIAUD, 2011). Segundo Alliaud (2013), registram-se dois circuitos paralelos que promoveram a formação docente no país - o advindo das escolas normais que visa atender o sistema educacional formal e o ofertado pelas universidades, que destina-se às diversas profissões.

Atualmente, o Sistema Nacional de Formación Docente argentino forma os docentes que lecionam para os níveis de Educação Inicial e Primária - denominados maestros e os que lecionam disciplinas específicas para o Ensino Secundário e Superior - chamados profesores. O Sistema é composto por instituições de caráter universitário e não universitário, cujas características são distintas. As universidades têm autonomia acadêmica e institucional, estando vinculadas ao Ministério de Cultura e Educação, que formula as políticas gerais juntamente com os Conselhos universitários. A formação dá-se em cursos de graduação e pós-graduação e o foco é colocado nos saberes específicos disciplinares. Em contrapartida, as instituições não universitárias designam os Institutos Superiores de Educação e os Institutos ou Escolas especializadas de orientação técnica que são vinculadas às províncias ou à municipalidade da Cidade Autônoma de Buenos Aires (C.A.B.A.). Tais instituições têm a oferta de cursos restringida à graduação e visam suprir a demanda de professores para o sistema educacional. A formação tem um caráter mais instrumental nas áreas humanísticas, artísticas e técnico-profissionais, sendo privilegiados os saberes pedagógicos específicos. 
Os principais problemas do Sistema Formador argentino referem-se às consequências geradas pela transferência da educação superior para as províncias, em 1994. A coexistência de subsistemas com diferentes características gerou uma fragmentação tanto no âmbito das províncias quanto no interior das instituições e entre as instituições formadoras, chegando-se ao não reconhecimento de títulos expedidos em uma jurisdição por outra. Por isso, tem-se buscado uma maior articulação entre as universidades e os institutos superiores (prevista na Ley Nacional de Educación Superior n. 24.521/1995), para se garantir um sistema integrado de formação docente (ALLIAUD, 2009).

A Argentina conta com 124 instituições públicas e privadas que oferecem formação de nível superior para professores de música, distribuídas em suas províncias e Cidade Autônoma de Buenos Aires, como está apresentado no quadro a seguir:

\begin{tabular}{|c|c|c|c|}
\hline \multirow{2}{*}{$\begin{array}{l}\text { TIPO DE INSTI- } \\
\text { TUIÇÃO }\end{array}$} & \multirow{2}{*}{$\begin{array}{l}\text { QUANTIDA- } \\
\text { DE DE INSTI- } \\
\text { TUIÇÕES }\end{array}$} & \multicolumn{2}{|c|}{ DISTRIBUIÇÃO POR PROVÍNCIAS } \\
\hline & & GESTÃO ESTATAL & GESTÃO PRIVADA \\
\hline $\begin{array}{c}\text { UNIVERSITÁ- } \\
\text { RIA }\end{array}$ & 14 & $\begin{array}{r}\text { Buenos Aires (1) } \\
\text { Santa Fe (2) } \\
\text { C.A.B.A (2) } \\
\text { Córdoba (1) } \\
\text { Cuyo (1) } \\
\text { Entre Ríos (1) } \\
\text { Río Negro (1) } \\
\text { San Juan (1) } \\
\text { San Luis (1) } \\
\text { TOTAL: } 11\end{array}$ & $\begin{array}{l}\text { C.A.B.A. (1) } \\
\text { Entre Ríos (1) } \\
\text { Santa Fe (1) }\end{array}$ \\
\hline
\end{tabular}




\begin{tabular}{|c|c|c|c|}
\hline \multirow{2}{*}{$\begin{array}{l}\text { TIPO DE INSTI- } \\
\text { TUIÇÃO }\end{array}$} & \multirow{2}{*}{$\begin{array}{l}\text { QUANTIDA- } \\
\text { DE DE INSTI- } \\
\text { TUIÇÕES }\end{array}$} & \multicolumn{2}{|c|}{ DISTRIBUIÇÃO POR PROVÍNCIAS } \\
\hline & & GESTÃO ESTATAL & GESTÃO PRIVADA \\
\hline $\begin{array}{l}\text { NÃO UNIVER- } \\
\text { SITÁRIA }\end{array}$ & 110 & $\begin{array}{r}\text { Buenos Aires (36) } \\
\text { Córdoba (8) } \\
\text { Santa Fe (6) } \\
\text { Neuquén (5) } \\
\text { Chubut (5) } \\
\text { C.A.B.A. (3) } \\
\text { Entre Ríos (5) } \\
\text { Catamarca (3) } \\
\text { Salta (3) } \\
\text { Santa Cruz (3) } \\
\text { Santiago del Estero (2) } \\
\text { Corrientes (2) } \\
\text { Jujuy (2) } \\
\text { La Pampa (2) } \\
\text { La Rioja (2) } \\
\text { Mendoza (2) } \\
\text { Misiones (2) } \\
\text { Tucumán (2) } \\
\text { Chaco (1) } \\
\text { Formosa (1) } \\
\text { San Luis (1) } \\
\text { TOTAL: } 96\end{array}$ & $\begin{array}{r}\text { C.A.B.A. (3) } \\
\text { Córdoba (3) } \\
\text { Entre Ríos (3) } \\
\text { Mendoza (2) } \\
\text { Buenos Aires (1) } \\
\text { Catamarca (1) } \\
\text { San Juan (1) }\end{array}$ \\
\hline
\end{tabular}

Quadro 1 - Distribuição, por províncias e tipo de gestão, das instituições universitárias e não universitárias que ofertam Profesorados en Música na Argentina

A maior parte dos cursos está concentrada em instituições de caráter não universitário - Conservatórios Superiores de Música e Institutos de Arte - e uma menor parcela está nas universidades, havendo uma distribuição desigual pelo território argentino, com concentração na província de Buenos Aires. Ressalta-se que, dos 543 cursos oferecidos por instituições não universitárias, 520 estão sob gestão estatal e apenas 23, sob a gestão privada. As universidades têm 61 cursos de formação de professores de música e também Ciclos de Profesorado para 
Licenciados, que possibilitam a formação docente aos egressos dos cursos de licenciatura.

Especificamente para a formação de professores na área de educação artística, encontram-se orientações nos Lineamientos Curriculares Nacionales para la Formación Docente Inicial (ARGENTINA, 2007a) prevendo que:

a) A modalidade de educação artística constitua-se em uma oferta de carreira específica de formação docente, tendo seu desenho curricular específico.

b) Nos Profesorados, seja preservada a formação da referida especificidade de cada uma das linguagens artísticas.

c) Nos Profesorados que formam para mais de um nível educacional, como algumas linguagens da educação artística, inclua-se, pelo menos, uma Didática Específica de cada nível de ensino ou modalidade, para qual o docente e está sendo formado, podendo até haver uma revisão na carga horária total do curso.

d) Dentro do campo da formação específica, os desenhos curriculares poderão considerar unidades curriculares comuns às distintas linguagens artísticas, mas a titulação final vai se referir apenas a uma linguagem.

e) A formação docente para a modalidade de educação artística dar-se-á em nível da Educação Superior, com duração de ao menos quatro anos, e proporcionará uma única titulação para o nível primário e secundário.

No que se refere à titulação concedida aos que fazem a formação docente na área de educação artística, o documento deve explicitar claramente a formação específica para cada subárea. Dessa maneira, o título atribuído ao concluinte do Profesorado en Música será Profesor de Música. Devem constar, também, informações quanto ao nível ou modalidade para os quais se está habilitando - Educación Artística; Educación Inicial; Educación Primaria; Educación Secundaria; Educación Especial - e a orientação - Orientación en ... (um só instrumento) (ARGENTINA, 2007a). A partir das Resoluções n. 74/2008 e n. 183/2012 que 
apresentaram o Cuadro de Nominaciones de Títulos (ARGENTINA 2008, 2012), a nomenclatura da titulação concedida pelos cursos de formação de professores de música na Argentina sofreram modificações, diminuindo a diversidade existente, o que possibilitou, também, a aceitação dos títulos em todo o território argentino.

Outro aspecto que afeta a educação musical e a formação de professores de música concerne a modelos que se fazem presentes na América Latina. A educação musical nos países latino-americanos, por ter sido fortemente influenciada pelos padrõeseuropeus, gerou uma hierarquização dos conhecimentos teóricos sobre os práticos, assim como a predileção do repertório erudito europeu sobre as composições populares ou nativas, constituindo-se em dilemas e contradições históricas que têm sido discutidos e estudados por pesquisadores.

Shifres e Gonnet (2015) caracterizam o Modelo Jesuíta e o Modelo Conservatório ${ }^{2}$ que podem auxiliar na compreensão das concepções de ensino de música latino-americanos. Com o Modelo Jesuíta, instalou-se a noção de unidade (religiosa, política, etc.) entendida como oposta à diversidade; e as formas expressivas preexistentes nas colônias foram classificadas como Arte menor ou artesanato (ligado ao uso prático de um objeto) em contraposição às Belas Artes (cujos objetos têm a finalidade de contemplação). A educação musical, que fez parte do processo evangelizador, buscou o desenvolvimento de destreza para a execução instrumental, dando-se ênfase à alfabetização e notação musicais (SHIFRES; GONNET, 2015).

O Modelo Conservatório, que se constituiu a partir das influências das concepções de arte e formação de artistas do final do século XVII e das bases do Modelo Jesuíta, sacralizou o texto musical como a base do conhecimento musical, determinou

\footnotetext{
2 "Conservatório, instituição muito antiga nascida na Itália no século XIV como instituição assistencial com o objetivo de 'conservar' e preservar da miséria os órfãos e abandonados ensinando-lhes algumas artes, música inclusive. Dedicada depois de poucos anos só à música, esta instituição foi adotada como modelo na Europa e no mundo ainda com mudanças e reformas sucessivas" (TAFURI, 2000, p. 115 apud MATEIRO, 2010, p. 34) (tradução nossa).
} 
os privilégios de aprendizagem musical, a valorização dos desempenhos individuais e a relação diática entre discípulo e mestre - aquela em que o vínculo intersubjetivo é sempre vertical. Este modelo vai, portanto, produzir uma hierarquia entre os sujeitos que se relacionam com a música - divisão músico/audiência, compositor/intérprete, além de atrelar-se às ideologias do talento. Resulta disso, que a educação musical dividiu-se entre formar músicos (sujeitos especializados) em espaços especializados como conservatórios e escolas de música, e formar ouvintes, nas escolas gerais e por meio dos meios de comunicação de massa (SHIFRES; GONNET, 2015).

Os outros modelos latino-americanos referem-se à formação de professores de música e foram delineados a partir da análise de 45 planos de estudo de oito países sul americanos 3 . São três modelos os quais têm ênfase nas áreas de música, pedagogia e artes, trazendo consigo diferentes concepções e apresentando características distintas quanto à oferta de disciplinas e à ênfase na área disciplinar ou pedagógica. A diversidade tanto de instituições formadoras - Faculdades de Educação, Faculdades de Belas Artes, Conservatórios de Música e Universidades, dentre outras - quanto de terminologias para as carreiras de professor de educação musical, também são fatores que incidem sobre os três modelos (MATEIRO, 2010).

O primeiro modelo de formação docente centra-se no conhecimento da música enquanto fenômeno, atividade e objeto de estudo. Dá-se ênfase às disciplinas de conteúdo musical, que ocupam cerca de $50 \%$ (cinquenta por cento) do total de horas do currículo. Nesse modelo de formação, o professor deve, antes de tudo, ser músico, o que muitas vezes ocasiona um conflito nos estudantes, no que se refere à identidade profissional. Muitos alunos desejam ser músicos, mas também trabalham como professores de música em diferentes espaços, não se limitando à escola básica (MATEIRO, 2010).

${ }^{3}$ Argentina (9); Bolívia (2); Brasil (15); Chile (8); Colômbia (1); Equador (2); Paraguai (1) e Venezuela (7) (MATEIRO, 2010, p. 31). 
O segundo modelo tem seus fundamentos na pedagogia, sendo prioritárias as disciplinas que se referem aos aspectos da educação, formação, ensino, aprendizagem, instrução e didática. Os cursos são oferecidos por Faculdades de Educação ou de Humanidades e o principal objetivo é formar professores nas várias áreas educacionais para atuar na educação primária e secundária. No caso da música, os cursos denominam-se Educação com especialidade em Educação Musical ou Pedagogia Musical (MATEIRO, 2010).

O terceiro modelo de formação de professores de música têm ênfase na área de artes e especialidade em música, artes visuais, artes cênicas, artes cinematográficas ou produção cultural. Nesses cursos, inicialmente ampliam-se os conhecimentos gerais dos diferentes campos artísticos e introduzem-se disciplinas relacionadas à literatura, filosofia e técnicas específicas de cada matéria. Depois de ter uma noção geral do campo da arte, o aluno escolhe uma especialidade para continuar sua formação (MATEIRO, 2010).

Ao se estabelecer uma relação entre os modelos de educação musical e os modelos de formação de professores de música, pode-se depreender que o Modelo Conservatório aproxima-se do primeiro modelo de formação docente que teve sua origem nos Conservatórios, nos quais os estudos visavam a formação do instrumentista. Segundo Fucci-Amato, (2006), a tradição dos Conservatórios foi levada a instituições de ensino superior e muitos cursos de Bacharelado em Música que mantêm em seus currículos um repertório essencialmente europeu, demonstram o predomínio do pensamento eurocêntrico na formação musical formal. Isso afetou a formação de professores de música em países da América Latina, pois, quando os programas de formação docente foram elaborados, apenas acrescentaram-se algumas disciplinas pedagógicas à formação superior de músicos, mantendo-se a concepção oriunda do Modelo Conservatório.

Ainda hoje, ensino e práticas musicais encontram-se impregnados por concepções eurocêntricas, apesar de já se 
vislumbrarem movimentos contrários a esse paradigma. Gainza (2015) recorda que a academia menosprezava a música da rua, havendo uma clara separação entre esta e a música da escola. Entretanto, atualmente, as músicas das ruas, assim como as das mídias tendem a ser mais valorizadas do ponto de vista musical. Em suas palavras:

Consequentemente, após mais de duas décadas de vigência monopolista do modelo neoliberal que, nos ensinos musicais do sistema educativo, privilegiou a teoria sobre a prática, observa-se nos últimos tempos a tendência a um retorno às atividades musicais e a uma aproximação à música popular por parte das academias. Um bom número de conservatórios e universidades oferece carreiras especializadas nos estilos e técnicas característicos das músicas folclóricas, urbanas e populares (GAINZA, 2015, p. 92).

Um exemplo disso é a abertura das instituições formadoras argentinas - universitárias e não universitárias - para cursos com ênfase no folclore, jazz e tango. Apesar dessa abertura e pelo fato de haver uma grande concentração dos cursos de formação de professores de música em Conservatórios, pode-se inferir que haja uma maior possibilidade de ainda se encontrarem características do Modelo Conservatório nas concepções e práticas pedagógicas nos Profesorados en Música.

Vincenzi (2015) acredita que para se modificar a formação de professores de música, deve-se promover mudanças nas instituições formadoras a partir das pessoas envolvidas diretamente com o trabalho: professores, diretores e não docentes. Para ele, é fundamental redesenhar a formação docente dentro do sistema educacional, vinculando-se à realidade dos alunos, dos docentes e das pessoas, em geral. Aróstegui e colaboradores (2015) alertam que os docentes têm que reconhecer as circunstâncias sociais e políticas que vão emparelhadas ao ato de ensinar e aprender. A formação inicial muitas vezes falha na compreensão dessa vertente política, inerente à educação, faltando aos professores de música uma 
maior conscientização sobre o componente político nas práticas de educação musical.

No âmbito das metodologias de ensino, Gainza (2015) traz uma discussão sobre a atual convivência de tendências opostas que incidem sobre as práticas docentes e o ensino musical nas escolas. Ela afirma que, nos dias de hoje, no campo da música, convivem as pedagogias ativas do século $X X$, os enfoques teóricos do tradicionalismo decimonônico e as abordagens cognitivistas típicas do neoliberalismo e da globalização. Observa-se um estado de fragmentação entre o conhecimento e a praxis musical, visto que a ênfase no lúdico - como reação ao racionalismo neoliberal - tem monopolizado o ensino musical, nas últimas décadas. Para a autora, é necessário que haja uma sólida preparação musical e pedagógica para os futuros professores, para que eles sejam capazes de escolher e decidir, além de serem flexíveis e criativos, assegurando a humanização da pedagogia musical (GAINZA, 2013).

\section{CONSIDERAÇÕES FINAIS}

Diversas ações apoiadas na legislação contribuíram para o fortalecimento da formação docente na Argentina, tais como a oferta dar-se em nível superior e por instituições credenciadas e a equiparação da titulação. Tudo isso recai, obviamente, sobre a formação de professores de música. A regulamentação da carga horária mínima de quatro anos para os cursos de formação docente e a definição da nomenclatura para a titulação expedida pelos Profesorados en Música solucionaram o problema da diversidade de denominações das titulações, trazendo uma maior mobilidade para alunos e a aceitação dos títulos dos egressos em todo o país. Entretanto, para Alliaud e Feeney (2014), faz-se necessário buscar unidade e integração do sistema de formação docente, para que se atenda ao desenvolvimento e interesses locais. Também deve-se adotar um discurso de revalorização dos docentes e uma abertura para a participação dos diversos atores da educação nos processos de construção curricular. 
A música, que integra a modalidade educação artística do sistema educacional, tem seu ensino previsto na Educação Infantil, Primária, Secundária e Superior, com diretrizes específicas para os currículos de cada nível. A formação de professores de música insere-se no nível superior e ocorre em instituições universitárias e não universitárias, como Conservatórios e Institutos de Arte, havendo uma distribuição desigual entre as províncias argentinas, o que se torna um fator desfavorável para suprir a demanda de docentes para a educação musical escolar no país.

A expressiva concentração de oferta de cursos de formação docente por Conservatórios de Música aponta para a possibilidade de serem encontradas características do Modelo Conservatório - apresentado por Shifres e Gonnet (2015) -, nos percursos de formação de professores de música. Entretanto, para que se possa fazer afirmações sobre este aspecto e sobre os modelos de formação de professores de música (MATEIRO, 2010) mais evidentes na Argentina, cabe investigar de maneira aprofundada, o que são objetivos da pesquisa em andamento, citada na introdução deste texto.

Há muitas metas a serem alcançadas, especialmente o que se relaciona à integração entre as instituições formadoras - universitárias e não universitárias - e entre o sistema formador e o sistema educacional, visando uma formação de professores conectada com as demandas da sociedade atual, para que se fortaleça o ensino de música nas escolas. 


\section{REFERÊNCIAS}

AISENSTEIN, Ángela; GUEVARA, Jennifer L.; FEIJOÓ, Macarena. Estado de la cuestión acerca de las investigaciones históricas sobre la formación inicial docente de maestros y profesores en Argentina en el período 1860-1990. Anuario de Historia de la Educación, v.18, n.1, p.133-155, 2017.

ALLIAUD, Andrea. Estado de situación de la formación docente en Argentina. Políticas y Desafíos a futuro, 2009. Disponível em: http://www2.congreso.gob.pe/sicr/cendocbib/con4 uibd.nsf/905AC0EE9B6B49C605257AFE0065F3FF/\$FILE/2estado_situacion.pdf. Acesso em: 16/03/2018.

- Impacto de la historia del magisterio argentino y la formación docente. I Encuentro Virtual de Escuelas Normales: "Orígenes del Magisterio Argentino. Anais... Programas Archivos escolares y Memoria de la Educación Argentina (MEDAR), 2011. Disponível em: http://www. bnm.me.gov.ar/redes_federales/archivos/encuentros/ encuentros/normales/docs/conferencia.pdf. Acesso em: 15/04/2018.

. La formación docente en Argentina. Aproximación a un análisis político de la situación. Itinerarios educativos, v.6, p.197-214, 2012-2013. Disponível em: http:// bibliotecavirtual.unl.edu.ar/ojs/index.php/Itinerarios/ issue/view/413/showToc Acesso em: 25/03/2018.

ARGENTINA. Ministerio de Educación. Ley de Educación Nacional n. 26.206/2006. Buenos Aires: Ministerio de Educación, 2006. Disponível em: <http://www.me.gov.ar/ doc_pdf/ley_de_educ_nac.pdf>. Acesso em: 05/06/2016.

. Consejo Federal de Educación. Instituto Nacional de Formación Docente. Resolución n. 24/2007. Lineamientos Curriculares Nacionales para la Formación Docente Inicial, Buenos Aires: CFE, 2007. (2007a).

Ministerio de Educación. Instituto Nacional de Formación Docente. Resolución n. 23/2007. Plan Nacional de Formación Docente 2007-2010, Buenos Aires: Ministerio de Educación, 2007. (2007b) 
- Consejo Federal de Educación. Resolución $n$. 74/2008, "Titulaciones para las carreras de Formación Docente" y "Cuadro de Nominaciones de Títulos", Buenos Aires: CFE, 2008.

- Consejo Federal de Educación. Resolución $n$. 74/2008, ANEXO 1. "Cuadro de Nominaciones de Títulos", Buenos Aires: CFE, 2008.

- Consejo Federal de Educación. Resolución $n$. 141/2011, ANEXO C. Educación Artística para 1er. y 2do. I 2do. y 3er. año del Ciclo Básico de la Educación Secundaria, Buenos Aires: CFE, 2011.

- Consejo Federal de Educación. Resolución $n$. 183/2012. Modificaciones del "Cuadro de Nominaciones de Títulos" aprobado por la Resolución CFE n. 74/08, Buenos Aires: CFE, 2012.

- Consejo Federal de Educación. Resolución $n$. 183/2012, ANEXO. Modificaciones de la Resolución CFE n. 74/08, Buenos Aires: CFE, 2012.

- Ministerio de Educación y Deportes. Instituto Nacional de Formación Docente. Resolución n. 286/2016. Plan Nacional de Formación Docente 2016-2021, Buenos Aires: Ministerio de Educación, 2016.

ARÓSTEGUI, José Luis; LOURO, Ana Lúcia; TEIXEIRA, Ziliane Lima de O.. Las políticas educativas de reforma y su impacto en la Educación Musical Escolar: de dónde venimos y hacia dónde podemos ir. Revista da ABEM, Londrina, v.23, n.35, p.24-34, jul./dez.2015.

FELDFEBER, M. Las políticas de formación docente. Voces en el Fénix, Buenos Aires, n.3, p.2629. Sep./2010.

FELDFEBER, Myriam; GLUZ, Nora. Las políticas educativas en Argentina: herencias de los ' 90 , contradicciones y tendencias de "nuevo signo". Educação e Sociedade, Campinas, v.32, n.115, p.339-356, abr./jun.2011. Disponível em: <http:// www.cedes.unicamp.br>. Acesso em: 31/07/2015. 
FUCCI-AMATO, R. C.. Educação pianística: o rigor pedagógico dos conservatórios. Revista Música Hodie, v.6, n.1, p.75-96, 2006.

GAINZA, Violeta $\mathrm{H}$. de. El rescate de la pedagogía musical: conferencias, escritos, entrevistas. Buenos Aires: Lumen, 2013.

. Movimientos y tendencias en la educación musical en la era de la diversidad: una mirada crítica. In: BATRES, E.; GAINZA, V. H. de. (Orgs.) La formación del educador musical latinoamericano. Guatemala, C. A.: Avanti - FLADEM, 2015, p.89-101.

LA PLATA, Dirección General de Cultura y Educación de la Provincia de Buenos Aires. Diseño curricular para la educación primaria: primer ciclo y segundo ciclo. La Plata: Dirección General de Cultura y Educación de la Provincia de Buenos Aires, 2018.

MATEIRO, Teresa. Músicos, pedagogos y arte-educadores con especialidad en educación musical: un análisis sobre la formación docente en países suramericanos. Profesorado: Revista de currículum y formación del profesorado, Granada, v.14, n.2, p.29-40, 2010.

MISURACA, María Rosa; MENGHINI, Raúl A.. La formación de docentes en la Argentina del siglo XXI: ¿consolidación de las tendencias de los '90?. Profesorado: Revista de Currículum y Formación de Profesorado, Granada, v.14, n.2, p.251-266, 2010.

SHIFRES, Favio; GONNET, Daniel. Problematizando la herencia colonial en la educación musical. Epistemus: Revista de estudios en Música, Cognición y Cultura, Buenos Aires, v.3, n.2, p.51-67, 2015.

VINCENZI, Alejandro de. La formación del educador musical latinoamericano. In: BATRES, E.; GAINZA, V. H. de. (Orgs.). La formación del educador musical latinoamericano. Guatemala, C. A.: Avanti - FLADEM, 2015, p.31-40. 